\title{
Interaction of Fullerenes with Organosilanes in the Ionization Chamber of a Mass Spectrometer under Electron Impact and the Reaction of $\mathrm{C}_{60}$ with Tetraphenylsilane in Solution under UV Irradiation
}

\author{
Yury I. Lyakhovetsky, Elena A. Shilova, Alexandra P. Pleshkova, Alexander I. Belokon, \\ Sergey O. Yakushin, and Boris L. Tumanskii \\ A.N. Nesmeyanov Institute of Organoelement Compounds of the Russian Academy of Sciences, 28 Vavilov Street, \\ GSP-1, V-334, Moscow 119991, Russia \\ Correspondence should be addressed to Yury I. Lyakhovetsky; yulyakh@ineos.ac.ru
}

Received 15 February 2016; Accepted 10 May 2016

Academic Editor: Khalique Ahmed

Copyright (c) 2016 Yury I. Lyakhovetsky et al. This is an open access article distributed under the Creative Commons Attribution License, which permits unrestricted use, distribution, and reproduction in any medium, provided the original work is properly cited.

\begin{abstract}
$\mathrm{C}_{60}$ was shown to react with organosilanes $\mathrm{Me}_{4} \mathrm{Si}, \mathrm{Ph}_{2} \mathrm{SiH}_{2}, \mathrm{Ph}_{2} \mathrm{MeSiH}, \mathrm{Ph}_{4} \mathrm{Si}$, and $\alpha$-naphthylphenylmethylsilane in the electron ionization ion source of a mass spectrometer with the transfer of the corresponding organic radicals ( $\mathrm{Me}, \mathrm{Ph}$, and $\alpha$-naphthyl) from the silanes to the fullerene. The reactions were accompanied by hydrogen addition to some products and hydrogen loss from them. $\mathrm{C}_{70}$ reacted with $\mathrm{Me}_{4} \mathrm{Si}$ analogously. A reaction mechanism involving homolytic dissociation of the silanes under electron impact to the corresponding organic radicals, which react further with $\mathrm{C}_{60}$ at the surface of the ionization chamber of the mass spectrometer to give the respective adducts, was offered. A mechanistic study of the reaction of $\mathrm{C}_{60}$ with $\mathrm{Me}_{4} \mathrm{Si}$ supported it. No silicon containing derivatives of the fullerenes were found. $\mathrm{C}_{60}$ reacted with $\mathrm{Ph}_{4} \mathrm{Si}$ in solution under UV irradiation in a similar fashion furnishing phenyl derivatives of the fullerene. These results provide an additional support to the hypothesis formulated earlier that the homolytic reactive mass spectrometry of fullerenes (the reactions of fullerenes with other species in the ionization chambers of mass spectrometers and their mass spectral monitoring) can predict the reactivity of them toward the same reagents in solution to a significant extent.
\end{abstract}

\section{Introduction}

Reactions occurring in the ionization chambers (ICs) of mass spectrometers may provide valuable information as to what reactions can be implemented successfully in solution or in the gas phase and solid state/phase. The most striking example of this is the discovery of fullerenes. They were first found as formed in the Smalley source of a mass spectrometer, and the 5-year target investigations resulted in the synthesis and isolation of $\mathrm{C}_{60}$ with an admixture of $\mathrm{C}_{70}$ in bulk amounts by a German-American group of scientists and pure $\mathrm{C}_{60}$ and $\mathrm{C}_{70}$ by a British group [1-3]. The mass spectrometers are designed for work with ions and thus, the most studied reactions performed in their ICs or by isolation of a certain ion and colliding it with a molecule in a special chamber are ion/molecule reactions [4-9]. However, the ICs of mass spectrometers are chemical reactors where other types of the reactions can occur. It primarily relates to homolytic reactions since free radicals are known as often forming in the ICs in relatively large amounts. They are generated, for example, owing to fragmentations of molecular ions or in the chemical ionization (CI) plasmas. Moreover, this type of the ionization chamber (IC) reactions is of a particular interest since such reactions are less dependent on solvent than the ionic processes and can be transferred to solution more easily. Certainly, homolytic bimolecular reactions occurring in ICs including those with fullerenes as reagents have been reported [10-18]. However, the amount of such examples is considerably less than of the examples of ion/molecule reactions. We also took part in these investigations of homolytic reactions and published a number of papers on such reactions of $\mathrm{C}_{60}$ and $\mathrm{C}_{70}$ with representatives of several classes of 
organic and organoelement compounds (perfluoroorganics, organo- and organoelement mercurials, ketones, aldehydes, and aromatics) occurring in the IC of a mass spectrometer under electron impact (EI) (here and throughout the text where appropriate, the term electron impact is used instead of conventional electron ionization since the reactions described involve homolytic dissociation of organosilanes initiated by the electron beam and the latter term is unsuitable). With that, our purpose was not to investigate these reactions in the IC as the end in themselves but to demonstrate that they can predict the reactivity of the fullerenes toward these reagents in solution or the solid phase/state. Actually, it was done by implementing the reactions of $\mathrm{C}_{60}$ with compounds of each abovementioned class under UV irradiation or thermally [19-26]. The present study continues investigations in this field. Organosilanes were chosen as reagents, and the choice was motivated by the following:

(1) Ion/molecule reactions of trimethylsilyl cation $\left[\left(\mathrm{CH}_{3}\right)_{3} \mathrm{Si}\right]^{+}$with a number of organic bases were performed with the use of chemical ionization (CI), ion cyclotron resonance (ICR), and Fourier transform ion cyclotron resonance (FTICR) techniques. The corresponding associates were detected. The most often employed source of the cation was tetramethylsilane [27]. Ren et al. reported the formation of $\left[\mathrm{C}_{60}\left(\mathrm{CH}_{3}\right)_{2} \mathrm{SiOCH}_{3}\right]^{+}$and $\left[\mathrm{C}_{60}\left(\mathrm{CH}_{3}\right)_{2} \mathrm{SiOSi}\left(\mathrm{CH}_{3}\right)_{3}\right]^{+}$ cations as the major products when $\mathrm{C}_{60}$ was reacted with trimethylsilylmethyl ether and hexamethyldisiloxane, respectively, immediately inside an IC under conditions of self-CI at $200^{\circ} \mathrm{C}$. The quantumchemical calculations showed that the most preferable structures of them were the structures of $\sigma_{\mathrm{Si}}$ adducts. Other ions found were $\left[\mathrm{C}_{60} \mathrm{Si}\left(\mathrm{CH}_{3}\right)_{3}\right]^{+}$, $\left[\mathrm{C}_{60} \mathrm{CH}_{3}\right]^{+}$, and $\left[\mathrm{C}_{60} \mathrm{SiH}\left(\mathrm{CH}_{3}\right)_{2}\right]^{+}$in the latter case [28]. All this suggested experiments that would demonstrate whether the reactions of $\mathrm{C}_{60}$ and $\mathrm{C}_{70}$ with organosilanes including tetramethylsilane can proceed in an IC under conditions favoring homolytic processes to occur which we applied in our abovementioned earlier studies $[19,24]$. If so, what products will be formed and can organosilyl radicals add to fullerenes under these conditions?

(2) The hypothesis that the results of homolytic reactions of $\mathrm{C}_{60}$ with other compounds occurring in the ICs of mass spectrometers can predict its reactivity toward the same compounds in solution was supported by the examples of a number of the compounds belonging to different classes (see above). However, to show the generality of the statement, species of other classes should be examined and organosilanes as widely spread organoelement compounds seemed to be suitable for this purpose.

\section{Experimental}

2.1. Materials. $\mathrm{C}_{60}(99.98 \%)$ was bought from a producer in Nizhnii Novgorod (Russia). $\mathrm{C}_{70}$ was prepared at the University of Sussex (Brighton, UK) and some of it was kindly given by Professor Roger Taylor. Tetramethylsilane (1), diphenylsilane (2), and diphenylmethylsilane (3) were of commercial grades. Samples of tetraphenylsilane (4) and optically active $\alpha$-naphthylphenylmethylsilane (5) were kindly supplied by Dr. Nikolai Loim. Electron ionization mass spectra $(\mathrm{m} / \mathrm{z}$

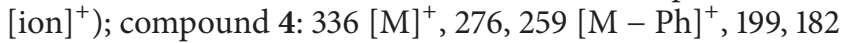
$[\mathrm{M}-2 \mathrm{Ph}]^{+}, 155,129,105[\mathrm{SiPh}]^{+}, 78[\mathrm{PhH}]^{+}, 53$. Compound 5: $248[\mathrm{M}]^{+}, 247[\mathrm{M}-\mathrm{H}]^{+}, 233[\mathrm{M}-\mathrm{Me}]^{+}, 202,170[\mathrm{M}-$ $\mathrm{PhH}]^{+}, 155[\mathrm{M}-\mathrm{PhH}-\mathrm{Me}]^{+}, 128[\text { naphthalene }]^{+}, 120[\mathrm{M}-$ naphthalene $]^{+}, 105[\mathrm{M}-\text { naphthalene }-\mathrm{Me}]^{+}, 78[\mathrm{PhH}]^{+}, 77$ $[\mathrm{Ph}]^{+}, 53$.

2.2. Methods. The reactions in an IC were conducted with a Kratos MS890a magnetic sector mass spectrometer at $70 \mathrm{eV}$ and the IC temperatures of $300-320^{\circ} \mathrm{C}$. Electron ionization mass spectra of silanes $\mathbf{4}$ and $\mathbf{5}$ were taken on the same instrument.

Three procedures were employed for implementing the reactions in the IC: $A, B$, and $C$. The $A$ and $B$ ones were described in [19]. Generally, a substrate $\left(\mathrm{C}_{60}\right.$ or $\left.\mathrm{C}_{70}\right)$ was applied onto the tip of a quartz needle from a benzene solution (one or two drops of the solution were applied), while a silane was introduced via a GLC chromatograph connected to the mass spectrometer (method $A$ ); a silane was placed into a capillary tube, while a fullerene was applied onto the outer surface of the tube near the open end and a probe with the tube inserted into the mass spectrometer $(\operatorname{method} B)$. With procedure $C$ used, a fullerene was applied onto the tip of a quartz needle, a blank space left on the needle, and then a silane applied onto it. The end of the needle was inserted into the mass spectrometer. When fullerene ion peaks appeared in the mass spectra and their intensities became more or less constant, the needle was moved deeper into the IC to provide a flow of the silane vapor.

Photochemical Reaction of $\mathrm{C}_{60}$ with Tetraphenylsilane (4). $\mathrm{C}_{60}$ $(6.2 \mathrm{mg}, 0.0086 \mathrm{mmol})$ was placed into a flask equipped with a magnetic stirrer. The flask was connected to a vacuum/argon system, and the air was replaced by argon. Decalin $(1.5 \mathrm{~mL})$ was added, and the suspension was agitated for $2 \mathrm{~h}$. Silane $4(38 \mathrm{mg}, 0.11 \mathrm{mmol})$ was then added, and the agitation was prolonged for $0.5 \mathrm{~h}$. The magenta solution $(0.4 \mathrm{~mL})$ was transferred by a capillary to a Pyrex ampoule (a J. Young NMR tube), degassed by a 10 -fold freeze-thaw procedure, and irradiated in the cavity of a Bruker EMX-10/12 X-band ( $\nu=$ 9.3 $\mathrm{GHz}$ ) digital electronic paramagnetic resonance (EPR) spectrometer by the light of a high pressure mercury lamp (1 kW; ARC lamp power supply, model 69920$)$ for $0.5 \mathrm{~h}$. The spectrometer was equipped with a Bruker $\mathrm{N}_{2}$-temperature controller, and the temperature of $283 \mathrm{~K}$ was maintained in the course of the experiment. The light of the lamp was focused onto the ampoule with a quartz lens and filtered through distilled water to remove the infrared component. The EPR spectra were recorded prior to irradiation and after $0.5 \mathrm{~h}$ irradiation at microwave power $0.5 \mathrm{~mW}, 100 \mathrm{kHz}$ magnetic field modulation of $0.5 \mathrm{G}$ amplitude, sweep time $83.89 \mathrm{~s}$, conversion time $40.96 \mathrm{msec}$, time constant $81.92 \mathrm{msec}$, and receiver gain $4.48 \times 10^{3}$. The digital field resolution was 2048 
TABLE 1: Ions of the main products formed in the reactions of fullerenes with organosilanes in the IC of a mass spectrometer under EI.

\begin{tabular}{|c|c|c|c|c|}
\hline Number & Fullerene & Silane & Method & Ions detected \\
\hline \multirow[b]{2}{*}{1} & $\mathrm{C}_{60}$ & Tetramethyl & $A$ & {$\left[\mathrm{H}_{k} \mathrm{C}_{60}\left(\mathrm{CH}_{3}\right)_{n}(-m \mathrm{H})\right]^{+}, n=1-8$} \\
\hline & $\mathrm{C}_{70}$ & The same & $A$ & $\begin{array}{c}{\left[\mathrm{C}_{70} \mathrm{CH}_{2}\right]^{+*},\left[\mathrm{HC}_{70} \mathrm{CH}_{3}\right]^{+\bullet},\left[\mathrm{CH}_{2} \mathrm{C}_{70} \mathrm{CH}_{3}\right]^{+\bullet},\left[\mathrm{C}_{70}\left(\mathrm{CH}_{3}\right)_{2}\right]^{+\bullet},} \\
{\left[\mathrm{HC}_{70}\left(\mathrm{CH}_{2}\right) \mathrm{CH}_{3}\right]^{+}}\end{array}$ \\
\hline 2 & $\mathrm{C}_{60}$ & Diphenyl & A & {$\left[\mathrm{C}_{60} \mathrm{C}_{6} \mathrm{H}_{4}\right]^{+\bullet},\left[\mathrm{C}_{60} \mathrm{Ph}\right]^{+},\left[\mathrm{HC}_{60} \mathrm{Ph}\right]^{+\bullet}$} \\
\hline 3 & $\mathrm{C}_{60}$ & Diphenylmethyl & $A$ & $\begin{array}{c}{\left[\mathrm{C}_{60} \mathrm{CH}_{2}\right]^{+\bullet},\left[\mathrm{HC}_{60} \mathrm{CH}_{3}\right]^{+\bullet},\left[\mathrm{C}_{60}\left(\mathrm{CH}_{3}\right)_{2}\right]^{+\bullet}, \mathrm{HC}_{60}\left(\mathrm{CH}_{2}\right) \mathrm{CH}_{3}^{+\bullet},} \\
{\left[\mathrm{H}_{2} \mathrm{C}_{60}\left(\mathrm{CH}_{3}\right)_{2}\right]^{+*},\left[\mathrm{C}_{66} \mathrm{C}_{3} \mathrm{H}_{10}\right]^{+\bullet},\left[\mathrm{C}_{60}\left(\mathrm{CH}_{2}\right)_{4}\right]^{+\bullet},\left[\mathrm{CH}_{2} \mathrm{C}_{60}\left(\mathrm{CH}_{2}\right)\left(\mathrm{CH}_{3}\right)_{2}\right]^{+\bullet},} \\
{\left[\mathrm{H}_{2} \mathrm{C}_{60}\left(\mathrm{CH}_{3}\right)_{4}\right]^{+\bullet},\left[\mathrm{C}_{60} \mathrm{C}_{6} \mathrm{H}_{4}\right]^{+\bullet},\left[\mathrm{HC}_{4} \mathrm{Ph}^{+\bullet},\left[\mathrm{CH}_{2} \mathrm{C}_{60} \mathrm{C}_{6} \mathrm{H}_{4}\right]^{+\bullet},\right.} \\
{\left[\mathrm{CH}_{3} \mathrm{C}_{60} \mathrm{Ph}\right]^{+\bullet}}\end{array}$ \\
\hline 4 & $\mathrm{C}_{60}$ & Tetraphenyl & $B$ & {$\left[\mathrm{C}_{60} \mathrm{C}_{6} \mathrm{H}_{4}\right]^{+\bullet},\left[\mathrm{HC}_{60} \mathrm{Ph}\right]^{+\bullet},\left[\mathrm{C}_{60} \mathrm{Ph}_{2}\right]^{+\bullet},\left[\mathrm{H}_{2} \mathrm{C}_{60} \mathrm{Ph}_{2}\right]^{+\bullet}$} \\
\hline 5 & $\mathrm{C}_{60}$ & $\alpha$-Naphthylphenylmethyl & C & $\begin{array}{c}{\left[\mathrm{C}_{60} \mathrm{CH}_{2}\right]^{+\bullet},\left[\mathrm{HC}_{60} \mathrm{CH}_{3}\right]^{+*},\left[\mathrm{C}_{60}\left(\mathrm{CH}_{2}\right)_{2}\right]^{+\bullet},\left[\mathrm{C}_{60}\left(\mathrm{CH}_{3}\right)_{2}\right]^{+\bullet}} \\
\mathrm{HC}_{60}\left(\mathrm{CH}_{2}\right) \mathrm{CH}_{3}^{+\bullet},\left[\mathrm{H}_{2} \mathrm{C}_{60}\left(\mathrm{CH}_{3}\right)_{2}\right]^{+\bullet},\left[\mathrm{C}_{60} \mathrm{C}_{3} \mathrm{H}_{10}\right]^{+\bullet},\left[\mathrm{C}_{60} \mathrm{C}_{6} \mathrm{H}_{4}\right]^{+\bullet} \\
{\left[\mathrm{HC}_{6 \mathrm{O}} \mathrm{Ph}^{+*},\left[\mathrm{CH}_{2} \mathrm{C}_{60} \mathrm{C}_{6} \mathrm{H}_{4}\right]^{+*},\left[\mathrm{C}_{60} \mathrm{C}_{10} \mathrm{H}_{6}\right]^{+\bullet},\left[\mathrm{HC}_{60}(\alpha-\mathrm{Naphthyl})\right]^{+\bullet}\right.}\end{array}$ \\
\hline
\end{tabular}

points per spectrum. The spectra processing was performed with the Bruker WIN-EPR.

Samples $(0.2 \mathrm{~mL})$ of the reaction mixture taken both before and after irradiation were diluted under argon by $1 \mathrm{~mL}$ of THF that was preliminary bubbled through by argon for $2 \mathrm{~min}$. They were subjected to atmospheric pressure chemical ionization mass spectrometry (APCI-MS) with Waters Micromass LCT Premier time-of-flight (TOF) mass spectrometer equipped with a Waters Acquity UPLC chromatograph (Milford, MA USA). The samples were syringed into the flow of a mixture of acetonitrile/ $\mathrm{H}_{2} \mathrm{O}$ (70/30) $(0.3 \mathrm{~mL} / \mathrm{min})$ after the chromatograph. Nitrogen was used as both nebulizing $(300 \mathrm{~L} / \mathrm{h})$ and cone gases $(55 \mathrm{~L} / \mathrm{h})$. The temperatures were of 150 and $300^{\circ} \mathrm{C}$ for the ion source and the probe, respectively. The corona discharge of $20 \mathrm{~mW}$ power was employed.

\section{Results and Discussion}

3.1. Reactions in the IC of a Mass Spectrometer. All organosilanes examined, 1-5, reacted with $\mathrm{C}_{60}$ in the IC of a mass spectrometer under EI with the transfer of the corresponding organic radicals from them to the fullerene. The reactions were accompanied by hydrogen addition and loss (Figures 1(a)-1(e) and Table 1) (at present, a number of other silanes and oligosilanes have been examined in the reactions in the IC of a mass spectrometer with $\mathrm{C}_{60}$ and $\mathrm{C}_{70}$ including $\mathrm{Et}_{3} \mathrm{SiH}$. The transfer of both methyl and ethyl radicals to the fullerenes was observed for this silane. The results of the investigations will be reported in subsequent publications).

Table 2 gives the monoisotopic $\left({ }^{12} \mathrm{C},{ }^{1} \mathrm{H}\right)$ spectrum for the reaction of tetramethylsilane (1) with $\mathrm{C}_{60}$. It was obtained by summarizing peaks of 52 magnetic scans, iterative use of the program SCIPE, and averaging the results over 3 runs [29]. Data listed in Table 2 demonstratively support the fact of hydrogen addition and loss. For example, the most intensive ions in the first group of the products that formed due to addition of one $\mathrm{CH}_{3}$ group to $\mathrm{C}_{60}$ are $736 \mathrm{Da}\left(\left[\mathrm{HC}_{60} \mathrm{CH}_{3}\right]^{+\bullet}\right.$, hydrogen addition) and $734 \mathrm{Da}\left(\left[\mathrm{C}_{60} \mathrm{CH}_{2}\right]^{+\bullet}\right.$, hydrogen loss).

The reaction of $\mathrm{C}_{70}$ with silane 1 proceeded similarly (Figure 1(f) and Table 1).
A question that requires attention is whether fragmentation processes could strongly influence the mass spectral pictures observed. Certainly, fragment ions, including rearrangement those, of the higher mass products contributed to the molecular ions of lower mass products. However, the electron ionization mass spectra of $\mathrm{C}_{60} \mathrm{Me}_{6}, \mathrm{C}_{60} \mathrm{Ph}_{2}, \mathrm{C}_{60} \mathrm{Ph}_{4}$, $\mathrm{C}_{70} \mathrm{Me}_{2}, \mathrm{C}_{70} \mathrm{Me}_{4}$, and $\mathrm{C}_{70} \mathrm{Me}_{8}$ showed the fragment ions (excluding $\mathrm{C}_{60}{ }^{+}$and $\mathrm{C}_{70}{ }^{+\bullet}$ ) to be noticeably less intensive than the molecular ones [30-32]. Moreover, a mixture of ethyl adducts of $\mathrm{C}_{60}$ was prepared from the reaction of $\mathrm{C}_{60}$ with diethyl ketone in decalin solution under UV irradiation [24]. Based on mass spectra obtained there for the mixture, after procedures of peak-summarizing over scans, we calculated the monoisotopic spectra. The ratio of the peak intensity of the $\left[\mathrm{C}_{60} \mathrm{CHCH}_{3} \text { and/or } \mathrm{C}_{60} \mathrm{CH}_{2} \mathrm{CH}_{2}\right]^{+\bullet}$ radical cations $(\mathrm{m} / \mathrm{z}$ 748) to that of $\left[\mathrm{HC}_{60} \mathrm{CH}_{2} \mathrm{CH}_{3}\right]^{+\bullet}$ one $(\mathrm{m} / z$ 750) turned out to be $0.20 \pm 0.08$ (standard deviation (SD)) in them. At the same time, the analogues value for $\left[\mathrm{C}_{60} \mathrm{CH}_{2}\right]^{+\bullet}(\mathrm{m} / z 734)$ and $\left[\mathrm{HC}_{60} \mathrm{CH}_{3}\right]^{+\bullet}(\mathrm{m} / z$ 736) was $0.71 \pm 0.22$ in the monoisotopic spectra for the reaction of $\mathrm{C}_{60}$ with $\mathbf{1}$ in the IC, that is, significantly greater than the former one. With that, it is most probably that some of the $748 \mathrm{Da}$ ions in the first case were due to the product from the solution reaction rather than fragment ions of the $750 \mathrm{Da}$ molecular ions. All this counts in favor of the fact that most of the $734 \mathrm{Da}$ ions in the case of the reaction in the IC did not represent fragment ions of $\left[\mathrm{HC}_{60} \mathrm{CH}_{3}\right]^{+\bullet}$ molecular radical cations. This conclusion finds further support in the following findings: molecular ions $\left[\mathrm{H}_{3} \mathrm{C}_{60} \mathrm{Ph}_{3}\right]^{+\bullet}$ and $\left[\mathrm{H}_{2} \mathrm{C}_{70} \mathrm{Me}_{2}\right]^{+\bullet}$ obtained from the corresponding products under electron ionization did not virtually fragment with the elimination of dihydrogen [31,32]. As mentioned in [24], a mixture of $\mathrm{n}$-butyl derivatives of $\mathrm{C}_{60}$ was earlier obtained by the reaction of $\mathrm{C}_{60}$ with ${ }^{\mathrm{n}} \mathrm{BuLi}$ followed by quenching the reaction mixture with aqueous $\mathrm{CF}_{3} \mathrm{COOH}$. The electron ionization spectrum of it also showed only insignificant fragmentation of $\left[\mathrm{HC}_{60}{ }^{\mathrm{n}} \mathrm{Bu}\right]^{+\bullet}$ with the loss of $\mathrm{H}_{2}$.

Thus, the peaks observed in the mass spectra recorded for the reactions performed in this study mostly are the molecular ions of the products with different numbers of addends to fullerenes. 

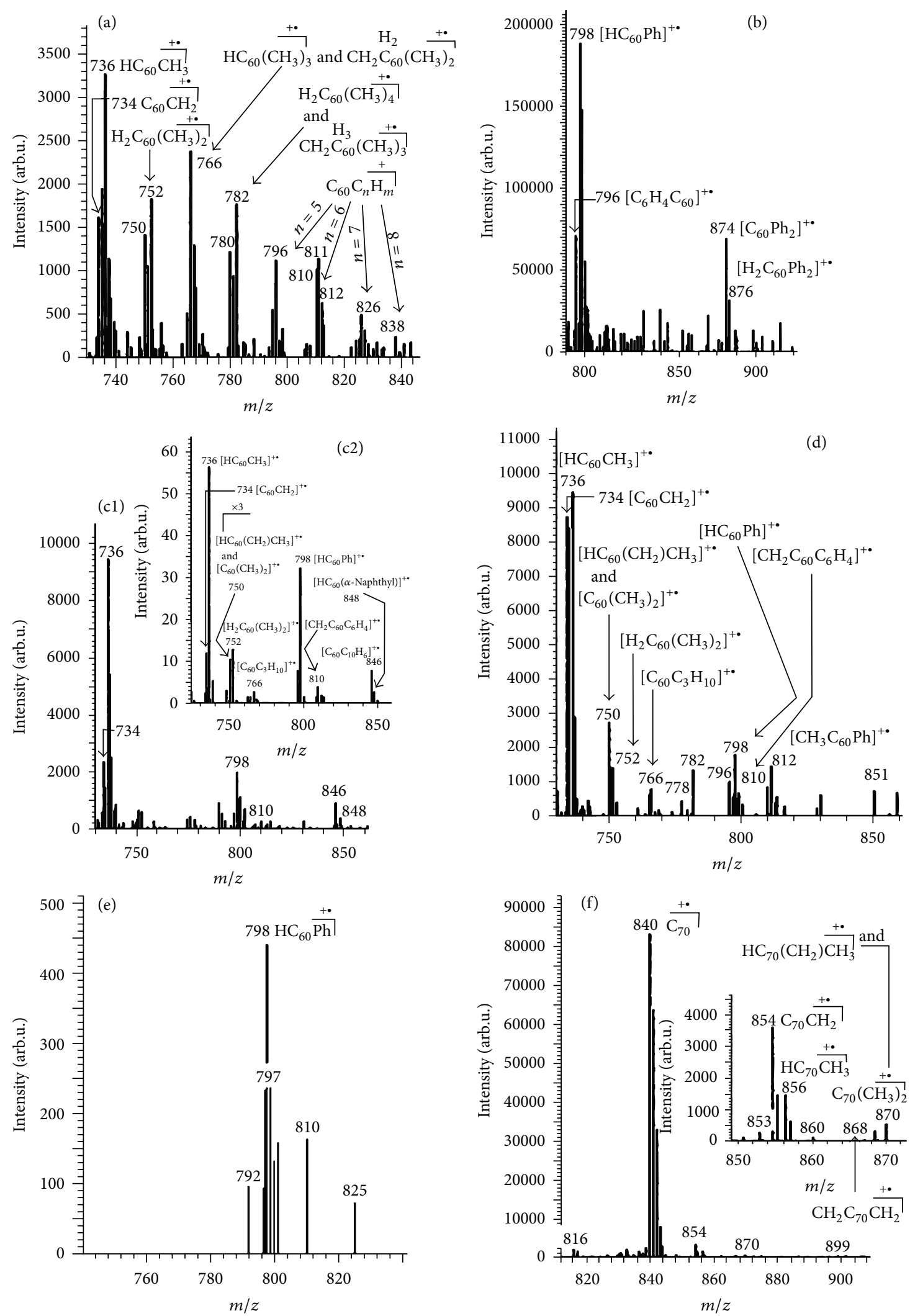

FIGURE 1: Electron ionization mass spectra in the high mass range from experiments in the IC of a mass spectrometer with $\mathrm{C}_{60}$ and (a) tetramethylsilane (1), (b) tetraphenylsilane (4), and (c1 and c2) $\alpha$-naphthylphenylmethylsilane (5): (c1) one-scan mass spectrum and (c2) monoisotopic $\left({ }^{12} \mathrm{C},{ }^{1} \mathrm{H}\right)$ spectrum derived from the spectrum obtained by peak-summarizing over 101 magnetic scans (the background peaks have been deleted), (d) diphenylmethylsilane (3), (e) diphenylsilane (2), and (f) with $\mathrm{C}_{70}$ and silane $\mathbf{1}$. 
TABLE 2: Monoisotopic mass spectrum (nominal masses and abundances $\left(I_{\text {rel }}\right)$ normalized to $100 \%$ total of each group) for the first four groups of the products from the reaction of $\mathrm{C}_{60}$ with silane $\mathbf{1}$ in the IC of a mass spectrometer under EI.

\begin{tabular}{|c|c|c|c|}
\hline Group & Nominal mass & $\begin{array}{c}\text { Ion } \\
{[\ldots]^{+}}\end{array}$ & $I_{\text {rel }}, \%$ \\
\hline \multirow{8}{*}{ I } & 733 & $\mathrm{C}_{60} \mathrm{CH}$ & 5 \\
\hline & 734 & $\mathrm{C}_{60} \mathrm{CH}_{2}$ & 29 \\
\hline & 735 & $\mathrm{C}_{60} \mathrm{CH}_{3}$ & 15 \\
\hline & 736 & $\mathrm{HC}_{60} \mathrm{CH}_{3}$ & 43 \\
\hline & 737 & $\mathrm{H}_{2} \mathrm{C}_{60} \mathrm{CH}_{3}$ & 3 \\
\hline & 738 & $\mathrm{H}_{3} \mathrm{C}_{60} \mathrm{CH}_{3}$ & 3 \\
\hline & 739 & $-^{\mathrm{a}}$ & 1 \\
\hline & 740 & $-^{\mathrm{a}}$ & 1 \\
\hline \multirow{8}{*}{ II } & 748 & $\mathrm{CH}_{2} \mathrm{C}_{60} \mathrm{CH}_{2}$ & 7 \\
\hline & 749 & $-^{\mathrm{a}}$ & 2 \\
\hline & 750 & $\begin{array}{c}\mathrm{C}_{60}\left(\mathrm{CH}_{3}\right)_{2} \\
\mathrm{HC}_{60}\left(\mathrm{CH}_{2}\right) \mathrm{CH}_{3}\end{array}$ & 55 \\
\hline & 751 & $\mathrm{C}_{60} \mathrm{C}_{2} \mathrm{H}_{7}$ & 11 \\
\hline & 752 & $\mathrm{H}_{2} \mathrm{C}_{60}\left(\mathrm{CH}_{3}\right)_{2}$ & 18 \\
\hline & 753 & $-^{\mathrm{a}}$ & 1 \\
\hline & 754 & $\mathrm{H}_{4} \mathrm{C}_{60}\left(\mathrm{CH}_{3}\right)_{2}$ & 4 \\
\hline & 755 & $-^{\mathrm{a}}$ & 1 \\
\hline \multirow{7}{*}{ III } & 762 & $\mathrm{C}_{60}\left(\mathrm{CH}_{2}\right)_{3}$ & 7 \\
\hline & 763 & $-^{\mathrm{a}}$ & 1 \\
\hline & 764 & $\mathrm{C}_{60} \mathrm{C}_{3} \mathrm{H}_{8}$ & 10 \\
\hline & 765 & $\mathrm{C}_{60} \mathrm{C}_{3} \mathrm{H}_{9}$ & 15 \\
\hline & 766 & $\begin{array}{c}\mathrm{HC}_{60}\left(\mathrm{CH}_{3}\right)_{3} \\
\mathrm{H}_{2} \mathrm{C}_{60}\left(\mathrm{CH}_{2}\right)\left(\mathrm{CH}_{3}\right)_{2}\end{array}$ & 48 \\
\hline & 767 & $\mathrm{C}_{60} \mathrm{C}_{3} \mathrm{H}_{11}$ & 9 \\
\hline & 768 & $\mathrm{H}_{3} \mathrm{C}_{60}\left(\mathrm{CH}_{3}\right)_{3}$ & 10 \\
\hline \multirow{8}{*}{ IV } & 776 & $\mathrm{C}_{60}\left(\mathrm{CH}_{2}\right)_{4}$ & 5 \\
\hline & 777 & - & 0 \\
\hline & 778 & $\mathrm{C}_{60} \mathrm{C}_{4} \mathrm{H}_{10}$ & 3 \\
\hline & 779 & $\mathrm{C}_{60} \mathrm{C}_{4} \mathrm{H}_{11}$ & 5 \\
\hline & 780 & $\begin{array}{c}\mathrm{C}_{60}\left(\mathrm{CH}_{3}\right)_{4}, \\
\mathrm{HC}_{60}\left(\mathrm{CH}_{2}\right)\left(\mathrm{CH}_{3}\right)_{3}, \\
\mathrm{H}_{2} \mathrm{C}_{60}\left(\mathrm{CH}_{2}\right)_{2}\left(\mathrm{CH}_{3}\right)_{2}\end{array}$ & 41 \\
\hline & 781 & $\mathrm{C}_{60} \mathrm{C}_{4} \mathrm{H}_{13}$ & $28^{\mathrm{b}}$ \\
\hline & 782 & $\begin{array}{c}\mathrm{H}_{2} \mathrm{C}_{60}\left(\mathrm{CH}_{3}\right)_{4} \\
\mathrm{H}_{3}\left(\mathrm{CH}_{2}\right)\left(\mathrm{CH}_{3}\right)_{3}\end{array}$ & 15 \\
\hline & 783 & $\mathrm{C}_{60} \mathrm{C}_{4} \mathrm{H}_{15}$ & 3 \\
\hline
\end{tabular}

${ }^{\mathrm{a}}$ The ions are not specified since their intensities fell within the error bounds. ${ }^{\mathrm{b}} \mathrm{A}$ contribution to the intensity from perfluorokerosene used as a mass calibrant is likely present.

There is another question that was underlined in the introduction: whether silicon containing derivatives of $\mathrm{C}_{60}$ and $\mathrm{C}_{70}$ were formed in the course of the reactions. It was impossible to catch them in the reactions of the fullerenes with the methyl containing organosilanes $(\mathbf{1}, \mathbf{3}$, and 5$)$ by a low-resolution technique since their nominal masses would coincide with those of the products of methyl additions to

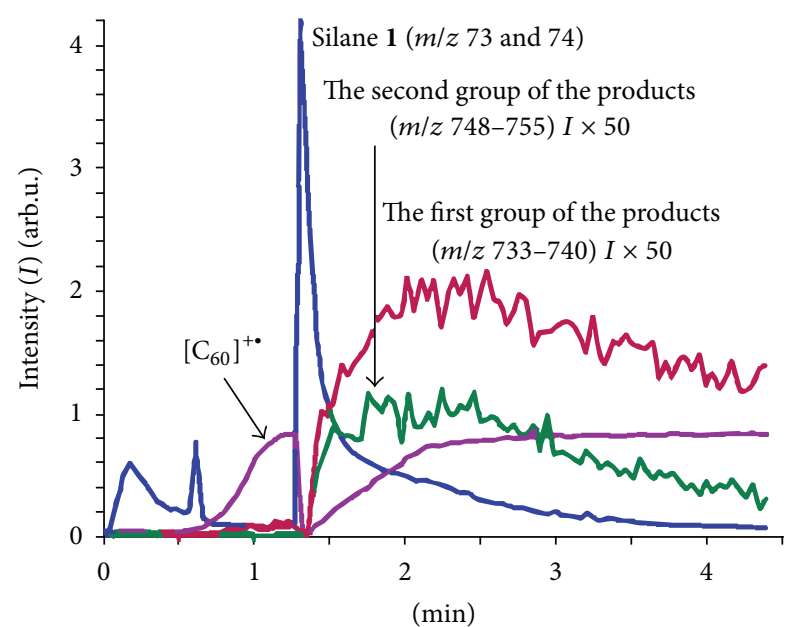

FIGURE 2: Mass chromatogram recorded in the course of an experiment with $\mathrm{C}_{60}$ and tetramethylsilane (1) effected in the IC of a mass spectrometer by protocol $A$. The traces of the other products detected behaved similarly.

the fullerene taking into account the hydrogen addition and loss mentioned above. However, no ion peaks that could be attributed assuredly to the silicon containing derivatives of $\mathrm{C}_{60}$ were found in the mass spectra for the reactions of the fullerene with silanes $\mathbf{2}$ and $\mathbf{4}$ bearing phenyl substituents only. A probable explanation of this fact will be given below, while discussing the reaction mechanism.

3.2. Mechanistic Studies. As for the reactions of fullerenes performed by protocol $A$ with all other compounds studied earlier which belonged to other classes [19, 24-26], the mass chromatograms show an interesting feature: the $\left[\mathrm{C}_{60}\right]^{+\bullet}$ or $\left[\mathrm{C}_{70}\right]^{+\bullet}$ intensity curves drop significantly when the peaks of silanes appear in the mass chromatograms and return to virtually the same level after the bulk of the peaks has passed. At these points the product traces appear (Figure 2).

This pattern of the curves provided possibility to elucidate some mechanistic questions: (i) Was the EI required for the reactions to occur? (ii) Where did the reactions occur, in the gas phase or at the IC surface? (iii) How did the reagents react, by ion/molecule or homolytic paths?

The experiments were conducted with $\mathrm{C}_{60}$ and 1 by the methods described in detail in $[19,24]$, the main point of which was the comparison of the summarized ion peak intensities of products with those obtained with the filament switched off or the ion-repelling electrode (repeller) potential (RP) set zero during the period when the bulk of the silane 1 peak was passing in the mass chromatograms. The filament was turned on or the RP returned to the standard $+30 \mathrm{~V}$ when the product peaks appeared (the summarized ion peak intensities of the first six groups of the products (up to the peaks at $m / z$ 805-816) were taken for the calculations). These runs displayed the amount of products obtained via a process involving EI activation to be $89 \% \pm 3 \%$ (SD) of their total amount. However, it is hardly possible that the remaining $11 \%$ arose because of the thermal reaction. Most 


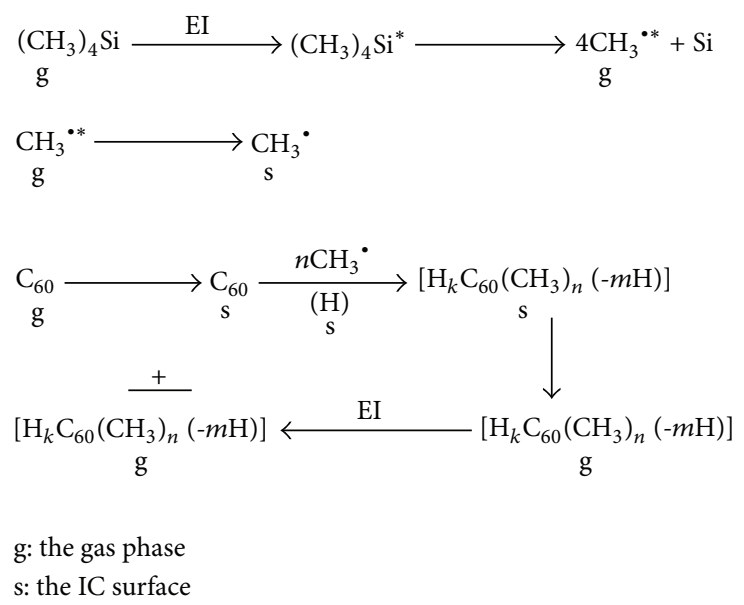

Scheme 1: Homolytic mechanism supposed for the reaction of $\mathrm{C}_{60}$ with silane $\mathbf{1}$ under EI in the ionization chamber (IC) of a mass spectrometer. ${ }^{*}$ In an excited state.

likely, they originated due to "the memory effect" of the IC surface. This was supported by the following: the method was slightly modified and each experiment was preceded with the experiment with the fullerene without 1 . The integrated intensity of the peaks which coincided with those of the products in the main experiments was subtracted from the latter peak intensities, respectively. The procedure reduced the above value to $\leq 1.2 \%$. It indicated that EI was required for the reaction to occur. The treatment of results of this group of the experiments with "the filament switched off" as described in the aforementioned references also showed that $87 \% \pm 3 \%$ $(97 \% \pm 1 \%$, if the background was subtracted) of the products were evaporated from the IC surface to be registered after electron ionization.

The experiments with the RP set to zero demonstrated that the amount of products related to that when the RP was standard $+30 \mathrm{~V}$ constituted $80 \% \pm 23 \%$ (when the summarized intensities of the background peaks were subtracted, the value turned out to be the same $(80 \%)$, but the scatter of the experimental data was noticeably greater. It is not surprising, since the obtainment of each experimental value involved two additional experiments in this case. However, the correction for those of the background peaks was not so essential here as in the case of elucidating whether the EI was required for the process to occur. Actually, in the former case, both intensity values compared were of the same order and significantly greater than those of the background peaks, while one of them was rather small in the latter case). This value indicates that cations were not involved in the process since otherwise the amounts of products would be awaited to increase at the zero RP (cf. the results of the ion/molecule reaction of the acetyl cation and acetone where the increase was more than sevenfold [24]). Since a mechanism via negative ions was hardly possible under applied condition, the most suitable one that would explain all experimental points observed is homolytic depicted in Scheme 1.

The scheme suggests activation of $\mathbf{1}$ to a superexcited state (the state where electronic excitation energy is higher than the first ionization energy of $\mathbf{1}$ [33]). The activated molecules of $\mathbf{1}$ dissociate liberating methyl radicals. The latter are formed with a great excess of the energy and should be deactivated to react with $\mathrm{C}_{60}$. The most profitable way for it under applied conditions is the collision with the IC surface. The deactivated radicals react with $\mathrm{C}_{60}$ at the surface to give the paramagnetic methyl derivative of the fullerene. This paramagnetic derivative is stabilized by addition of a hydrogen atom or the next radical, or by hydrogen loss. The reaction proceeds further similarly furnishing groups of methyl and methylene derivatives of $\mathrm{C}_{60}$. The hydrogen atoms are supplied by organic or organoelement compounds adsorbed at the IC surface and probably by 1 itself also adsorbed at the surface $[19,24]$. All products vaporize from the surface, undergo ionization, and are registered as their molecular ions.

The reactions of $\mathrm{C}_{60}$ with silanes $\mathbf{2}-\mathbf{5}$ and $\mathrm{C}_{70}$ with $\mathbf{1}$ are believed to occur in similar homolytic fashions.

The homolytic mechanism of the reactions exemplified by Scheme 1 explains why silicon containing derivatives were not found among the reaction products; possessing great excesses of the energy, the silicon intermediates simply decomposed before reaching the IC surface producing organic radicals.

It also answers the question why the products of the reactions of $\mathrm{C}_{60}$ with trimethylsilylmethyl ether and hexamethyldisiloxane reported by Chinese chemists were of a different type [28]. The authors performed the reactions under conditions of self-CI at $200^{\circ} \mathrm{C}$. At this temperature, fullerenes and their derivatives do not virtually vaporize from the IC surface, and they registered products of ion/molecule reactions occurring in the gas phase. At the same time, we detected products of $\mathrm{radical} / \mathrm{molecule}$ reactions occurring at the IC surface.

3.3. Reaction in Solution under UV Irradiation. The aforementioned results suggested runs that would display whether similar homolytic reactions could be implemented in solution. The simplest substitute in solution for electron irradiation employed in the gas phase is UV irradiation by the UV light of the quartz range (350-200 nm). However silane 1 does not absorb the light in this range, and its photolysis was 
carried out under UV irradiation by light of the vacuum range $(200-100 \mathrm{~nm})[34,35]$. Thus, it cannot react with fullerenes under quartz range UV irradiation, at least, via a mechanism involving its homolytic dissociation similar to that depicted in Scheme 1. At the same time, silanes with aromatic substituents, for example, tetraphenylsilane (4), absorb light of the quartz range $[36,37]$. This suggested choosing silane 4 as a reagent for the reaction with $\mathrm{C}_{60}$ in solution.

Actually, when a decalin solution of $\mathrm{C}_{60}$ and silane 4 was irradiated by the light of a high pressure mercury lamp in the cavity of an EPR spectrometer for $0.5 \mathrm{~h}$, a reaction occurred. The reaction was monitored by EPR spectroscopy and APCIMS; namely, the EPR spectra were recorded and samples for APCI-MS were taken before and after $30 \mathrm{~min}$ irradiation. No signal was recorded in the former EPR spectrum, while a signal from superposition of the signals from different radicals with an average $g$-factor of 2.0021, adducts of monoand polyaddition of the phenyl radical to the fullerene, was found in the latter spectrum. Besides, a signal with $g=$ 2.00135 was present in the spectrum and assigned to ${ }^{3} \mathrm{C}_{60}$, $\mathrm{C}_{60}$ in the lowest triplet state (Figure 3(a)) $[38,39]$. Switching off UV irradiation led to a decrease in intensity of the signal of the fullerene derivatives because of dimerization of the "alkyl type" fullerenyl radicals. As a result, only the more stable fullerenyl radicals of "allyl- or cyclopentadienyl-type" were observed (Figure 3(b)).

The APCI-MS analysis in the positive mode of the reaction mixture diluted by $\mathrm{THF}$ showed the presence of protonated products of the additions of four and five phenyl radicals to $\mathrm{C}_{60}$ (ions with $m / z 1029$ and 1106, resp.). Besides, the mass spectrum displayed a peak at $\mathrm{m} / z 1076$ that can be ascribed to the $\left[\mathrm{O}_{3} \mathrm{C}_{60} \mathrm{Ph}_{4}\right]^{+\bullet}$ radical ion formed from products of the quadruple addition of phenyl radicals to $\mathrm{C}_{60}$ during the APCI-MS analysis (Figure 3(c)). No products were found in the mass spectrum of the unirradiated reaction mixture.

Thus, the reactions of $\mathrm{C}_{60}$ with tetraphenylsilane in the IC of a mass spectrometer under EI and in decalin solution under UV irradiation proved to be, as awaited, of a similar type: the addition of phenyl radicals forming due to homolytic dissociation of the silane to the fullerene occurred.

\section{Conclusions}

$\mathrm{C}_{60}$ and organosilanes $\mathrm{R}_{1} \mathrm{R}_{2} \mathrm{R}_{3} \mathrm{R}_{4} \mathrm{Si}\left(\mathbf{1}: \mathrm{R}_{1}-\mathrm{R}_{4}=\mathrm{Me} ; 2\right.$ : $\mathrm{R}_{1}$ and $\mathrm{R}_{2}=\mathrm{Ph}, \mathrm{R}_{3}$ and $\mathrm{R}_{4}=\mathrm{H} ; 3: \mathrm{R}_{1}$ and $\mathrm{R}_{2}=\mathrm{Ph}, \mathrm{R}_{3}=\mathrm{Me}$, and $\mathrm{R}_{4}=\mathrm{H} ; 4: \mathrm{R}_{1}-\mathrm{R}_{4}=\mathrm{Ph} ; 5: \mathrm{R}_{1}=\alpha$-naphthyl, $\mathrm{R}_{2}=\mathrm{Ph}, \mathrm{R}_{3}=$ $\mathrm{Me}$, and $\mathrm{R}_{4}=\mathrm{H}$ ) interacted in the IC of a mass spectrometer under EI at $300-320^{\circ} \mathrm{C}$ with the transfer of the corresponding organic radicals ( $\mathrm{Me}, \mathrm{Ph}$, and $\alpha$-naphthyl) from the silanes to the fullerene. The reaction of $\mathrm{C}_{70}$ with $\mathrm{Me}_{4} \mathrm{Si}$ proceeded in a similar fashion. No adducts of organosilyl radicals to the fullerenes were found. The reaction mechanism was proposed and experimentally supported as homolytic involving excitation of the silane molecules to superexcited states followed by dissociation of the excited molecules to give $\mathrm{R}_{n}$ radicals in the gas phase. The radicals formed react with fullerenes at the IC surface to give paramagnetic derivatives of the fullerenes.

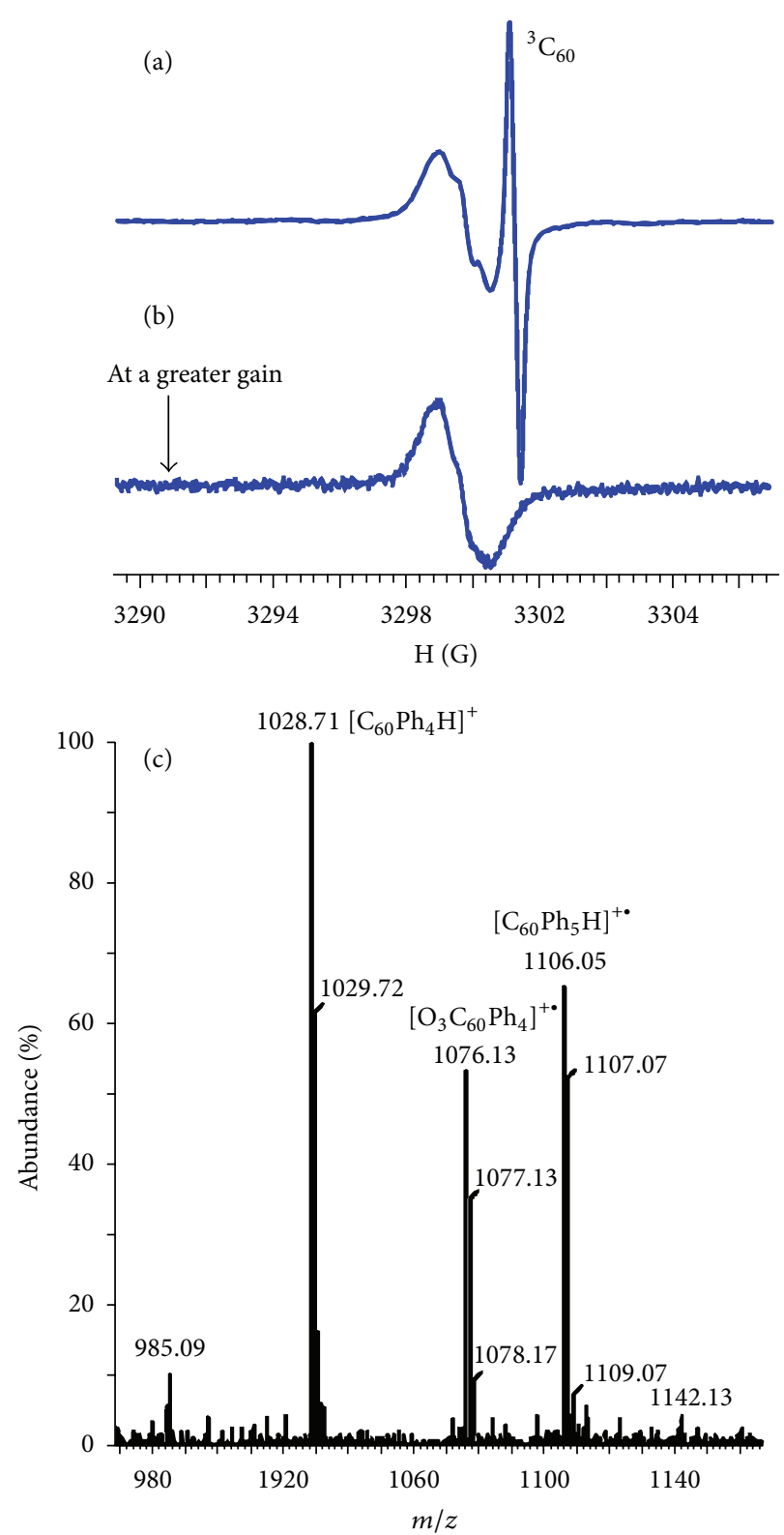

FIgURE 3: (a) and (b) EPR spectra recorded at $283 \mathrm{~K}$ after 30 min UV irradiation of the $\mathrm{C}_{60}$, silane 4 reaction mixture with the UV light on and off, respectively. (c) Positive mode APCI mass spectrum in the high mass region of a THF diluted sample of the reaction mixture taken after $30 \mathrm{~min}$ irradiation.

The derivatives are stabilized by addition of the next radical or hydrogen addition, or loss. All products vaporize from the surface and are identified after electron ionization.

The results obtained are different from ones reported by Ren et al. [28]. They detected ions of silicon containing derivatives of $\mathrm{C}_{60}$ while performing the reactions of the fullerene with trimethylsilylmethyl ether and hexamethyldisiloxane under conditions of self-CI at $200^{\circ} \mathrm{C}$. This difference is explainable by the fact that the gas-phase ion/molecule reactions occurred under the conditions they used whereas in our 
case, the homolytic reaction occurred which involved the formation of the intermediate alkyl or aryl radicals in the gas phase followed by their interaction with fullerenes at the IC surface. It is highly probable that had the authors of the above research worked with the silanes examined in the present paper, they would also have found the corresponding silicon containing products of the ion/molecule reactions.

In line with results obtained in the mass spectrometer, $\mathrm{C}_{60}$ reacted with $\mathrm{Ph}_{4} \mathrm{Si}$ in decalin solution under UV light of the quartz range with the transfer of phenyl radicals from the latter to the former. This provides an additional evidence to the hypothesis suggested earlier that the homolytic reactive mass spectrometry of fullerenes (the reactions of fullerenes with other species in the ICs of mass spectrometers) can tell chemists what homolytic fullerene reactions can be implemented successfully in solution or in the solid state/phase and by what means. Such tests for the reactivity of fullerenes possess those advantages that require tiny amounts of reagents; the experiments are rather quick and the main products can be identified in the course of them. We also anticipate that all this is valid not only for fullerenes but also for other substrates and here is a good area for investigations.

\section{Disclosure}

Shulich Faculty of Chemistry, Technion-Israel Institute of Technology, 3200 Haifa, Israel, is the present address of Boris L. Tumanskii.

\section{Competing Interests}

The authors declare that there is no conflict of interests regarding the publication of this paper.

\section{Acknowledgments}

The financial support to this study from MSIT RF (Grant nos. 40.012.1.1.1147 and 41.002.1.1.1405) is gratefully acknowledged. The authors are also thankful to the late Professor R. Taylor for $\mathrm{C}_{70}$ and to Dr. N. Loim for samples of two organosilanes.

\section{References}

[1] H. W. Kroto, J. R. Heath, S. C. O'Brien, R. F. Curl, and R. E. Smalley, "C60: buckminsterfullerene," Nature, vol. 318, no. 6042, pp. 162-163, 1985.

[2] W. Krätschmer, L. D. Lamb, K. Fostiropoulos, and D. R. Huffman, "Solid $\mathrm{C}_{60}$ : a new form of carbon," Nature, vol. 347, no. 6291, pp. 354-358, 1990.

[3] R. Taylor, J. P. Hare, A. K. Abdul-Sada, and H. W. Kroto, "Isolation, separation and characterisation of the fullerenes $\mathrm{C}_{60}$ and $\mathrm{C}_{70}$ : the third form of carbon," Journal of the Chemical Society, Chemical Communications, no. 20, pp. 1423-1425, 1990.

[4] J. S. Brodbelt, "Analytical applications of ion-molecule reactions," Mass Spectrometry Reviews, vol. 16, no. 2, pp. 91-110, 1997.

[5] S. Gronert, "Mass spectrometric studies of organic ion/molecule reactions," Chemical Reviews, vol. 101, no. 2, pp. 329-360, 2001.
[6] L. Operti and R. Rabezzana, "Gas-phase ion chemistry in organometallic systems," Mass Spectrometry Reviews, vol. 25, no. 3, pp. 483-513, 2006.

[7] D. K. Böhme, "Gaseous ions and chemical mass spectrometry," Canadian Journal of Chemistry, vol. 86, no. 3, pp. 177-198, 2008.

[8] D. K. Bohme, "Buckminsterfullerene cations: new dimensions in gas-phase ion chemistry," Mass Spectrometry Reviews, vol. 28, no. 4, pp. 672-693, 2009.

[9] S. Osburn and V. Ryzhov, "Ion-molecule reactions: analytical and structural tool," Analytical Chemistry, vol. 85, no. 2, pp. 769778, 2013.

[10] C. N. McEwen and M. A. Rudat, "Radical trapping in a mass spectrometer ion source. 1," Journal of the American Chemical Society, vol. 103, no. 15, pp. 4343-4349, 1981.

[11] M. A. Rudat and C. N. McEwen, "Gas-phase radical structures. Radical trapping. 2," Journal of the American Chemical Society, vol. 103, no. 15, pp. 4349-4354, 1981.

[12] C. N. McEwen and M. A. Rudat, "Isomerization of gas-phase hydrocarbon ions. Radical trapping. 3," Journal of the American Chemical Society, vol. 103, no. 15, pp. 4355-4359, 1981.

[13] D. Stöckl and H. Budzikiewicz, "Molecule/radical reactions prior to ionization under negative chemical ionization conditions," Organic Mass Spectrometry, vol. 17, no. 8, pp. 376-381, 1982.

[14] G.-R. Her, G. G. Dolnikowski, and J. Throck Watson, "Hydrogen radical/molecule reactions in the negative ion mass spectrometry of dicyano-methane derivatives of 9-fluorenone and benzophenone," Organic Mass Spectrometry, vol. 21, no. 6, pp. 329-334, 1986.

[15] C. N. McEwen, "Radicals in analytical mass spectrometry," Mass Spectrometry Reviews, vol. 5, no. 4, pp. 521-547, 1986.

[16] C. N. McEwen, R. G. McKay, and B. S. Larsen, " $\mathrm{C}_{60}$ as a radical sponge," Journal of the American Chemical Society, vol. 114, no. 11, pp. 4412-4414, 1992.

[17] Y. V. Vasilev, A. Hirsch, R. Taylor, and T. Drewello, "Hydrogen

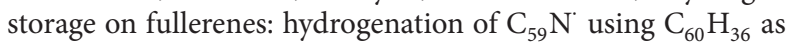
the source of hydrogen," Chemical Communications, no. 15, pp. 1752-1753, 2004.

[18] R. F. Tuktarov, R. V. Khatymov, and M. V. Muftakhov, "Processes of hydrogenation of trifluoromethylfullerenes in the mass spectrometer ion source," High Energy Chemistry, vol. 42, no. 6, pp. 472-477, 2008.

[19] Y. I. Lyakhovetsky, E. A. Shilova, B. L. Tumanskii et al., "Trifluoromethylation of [60]- and [70]fullerene in the ionization chamber of a mass spectrometer," Fullerene Science and Technology, vol. 7, no. 2, pp. 263-287, 1999.

[20] E. A. Shilova, Y. I. Lyakhovetsky, B. L. Tumanskii, A. I. Belokon', and Y. S. Nekrasov, "Alkylation and phenylation of [60]- and [70]-fullerenes by the reaction with ketones in the ionization chamber of a mass spectrometer," Mendeleev Communications, vol. 9, no. 5, pp. 176-177, 1999.

[21] A. D. Darwish, A. K. Abdul-Sada, A. G. Avent, Y. I. Lyakhovetsky, E. A. Shilova, and R. Taylor, "Unusual addition patterns in trifluoromethylation of [60]fullerene," Organic and Biomolecular Chemistry, vol. 1, no. 17, pp. 3102-3110, 2003.

[22] Y. I. Lyakhovetsky, V. V. Bashilov, E. A. Shilova, V. I. Sokolov, Y. S. Nekrasov, and R. Taylor, "Trifluoromethylation of $\mathrm{C}_{60}$ and $\mathrm{C}_{70}$ with Mercury(II) trifluoroacetate," Fullerenes Nanotubes and Carbon Nanostructures, vol. 17, no. 2, pp. 85-98, 2009.

[23] Y. I. Lyakhovetsky, E. A. Shilova, V. V. Bashilov, V. I. Sokolov, Y. S. Nekrasov, and B. L. Tumanskii, "Homolytic reactive mass 
spectrometry of fullerenes: interaction of $\mathrm{C}_{60}$ and $\mathrm{C}_{70}$ with organo- and organoelement mercurials in the electron impact ion source of a mass spectrometer; EPR, CIDEP, and MS studies of several analogous reactions of $\mathrm{C}_{60}$ performed in solution," The Journal of Physical Chemistry A, vol. 113, no. 49, pp. 1370013710, 2009.

[24] E. A. Shilova, Y. I. Lyakhovetsky, A. I. Belokon et al., "Homolytic reactive mass spectrometry of fullerenes: Interaction of $\mathrm{C}_{60}$ and $\mathrm{C}_{70}$ with ketones in the electron impact ion source of a mass spectrometer and the comparison of results with those of photochemical reactions of $\mathrm{C}_{60}$ with several ketones in solution," Journal of the American Society for Mass Spectrometry, vol. 22, no. 11, pp. 2021-2032, 2011.

[25] Y. I. Lyakhovetsky, A. P. Pleshkova, E. A. Shilova et al., "A comparative study of homolytic reactions of fullerenes with aldehydes in a mass spectrometer under electron impact and in solution under UV irradiation," European Journal of Mass Spectrometry, vol. 18, no. 4, pp. 361-376, 2012.

[26] Y. I. Lyakhovetsky, E. A. Shilova, A. I. Belokon, L. I. Panz, and B. L. Tumanskii, "Homolytic reactive mass spectrometry of fullerenes: peculiarities of the reactions of $\mathrm{C}_{60}$ with aromatic compounds in the ionization chambers of mass spectrometers and in solution," Journal of the American Society for Mass Spectrometry, vol. 24, no. 4, pp. 579-588, 2013.

[27] J. A. Stone, "Gas-phase association reactions of trimethylsilylium $\left(\left(\mathrm{CH}_{3}\right)_{3} \mathrm{Si}^{+}\right)$with organic bases," Mass Spectrometry Reviews, vol. 16, no. 1, pp. 25-49, 1997.

[28] X.-Y. Ren, Z.-Y. Liu, T.-Q. Zhu, X.-H. Wen, and X.-H. Guo, "Gas-phase ion-molecule reactions of neutral $\mathrm{C}_{60}$ with the plasmas of trimethylsilyl ethers and ab initio study on the structures," Journal of Molecular Structure: THEOCHEM, vol. 664-665, pp. 247-254, 2003.

[29] Y. N. Sukharev, V. F. Sizoi, and Y. S. Nekrasov, "The computer processing and interpretation of mass spectral information. VI-computing the isotopic spectrum of assumed composition," Organic Mass Spectrometry, vol. 16, no. 1, pp. 23-25, 1981.

[30] H. Al-Matar, A. K. Abdul-Sada, A. G. Avent et al., "Isolation and characterisation of symmetrical $\mathrm{C}_{60} \mathrm{Me}_{6}, \mathrm{C}_{60} \mathrm{Me}{ }_{5} \mathrm{Cl}$ and $\mathrm{C}_{60} \mathrm{Me}_{5} \mathrm{O}_{2} \mathrm{OH}$, together with unsymmetrical $\mathrm{C}_{60} \mathrm{Me}_{5} \mathrm{O}_{3} \mathrm{H}$, $\mathrm{C}_{60} \mathrm{Me}_{5} \mathrm{OOH}, \mathrm{C}_{60} \mathrm{Me}_{4} \mathrm{PhO}_{2} \mathrm{OH}$, and $\mathrm{C}_{60} \mathrm{Me}_{12}$; fragmentation of methylfullerenols to $\mathrm{C}_{58}$," Journal of the Chemical Society, Perkin Transactions 2, vol. 2, no. 1, pp. 53-58, 2002.

[31] P. R. Birkett, A. G. Avent, A. D. Darwish, H. W. Kroto, R. Taylor, and D. R. M. Walton, "Preparation and characterisation of unsymmetrical $\mathrm{C}_{60} \mathrm{Ph}_{4}$ and symmetrical $\mathrm{C}_{60} \mathrm{Ph}_{2}$ : the effect of regioselective nucleophilic attack upon $\mathrm{C}_{60} \mathrm{Cl}_{6}$," Journal of the Chemical Society. Perkin Transactions 2, no. 3, pp. 457-461, 1997.

[32] H. Al-Matar, A. K. Abdul Sada, A. G. Avent, R. Taylor, and X.W. Wei, "Methylation of [70]fullerene," Journal of the Chemical Society, Perkin Transactions 2, no. 7, pp. 1251-1256, 2002.

[33] V. I. Makarov and L. S. Polak, "Excited and superexcited electronic states of atoms and molecules and their role in radiation chemistry," Khimiya Vysokikh Energiy, vol. 4, no. 1, pp. 3-23, 1970, English Translation: High Energy Chemistry, vol. 4, p. 1, 1970.

[34] L. Gammie, C. Sandorfy, and O. P. Strausz, "Photochemistry of silicon compounds. 6 . The $147-\mathrm{nm}$ photolysis of tetramethylsilane," The Journal of Physical Chemistry, vol. 83, no. 24, pp. 30753083, 1979.
[35] E. Bastian, P. Potzinger, A. Ritter, H. P. Schuchmann, C. von Sonntag, and G. Weddle, "The direct photolysis of tetramethylsilane in the gas and liquid phases," Berichte der Bunsengesellschaft für physikalische Chemie, vol. 84, no. 1, pp. 56-62, 1980.

[36] M. Wakasa, Y. Sakaguchi, and H. Hayashi, "The first direct observation of magnetic field effects on the dynamic behavior of radical pairs involving group 14 silicon and germanium centered radicals," Journal of the American Chemical Society, vol. 114 , no. 21, pp. 8171-8176, 1992.

[37] M. G. Steinmetz, "Organosilane photochemistry," Chemical Reviews, vol. 95, no. 5, pp. 1527-1588, 1995.

[38] G. L. Closs, P. Gautam, D. Zhang, P. J. Krusic, S. A. Hill, and E. Wasserman, "Steady-state and time-resolved direct detection EPR spectra of fullerene triplets in liquid solution and glassy matrices. Evidence for a dynamic Jahn-Teller effect in triplet $\mathrm{C}_{60}$," The Journal of Physical Chemistry, vol. 96, no. 13, pp. 52285231, 1992.

[39] M. R. Fraelich and R. B. Weisman, "Triplet states of C60 and C70 in solution: long intrinsic lifetimes and energy pooling," The Journal of Physical Chemistry, vol. 97, no. 43, pp. 11145-11147, 1993. 

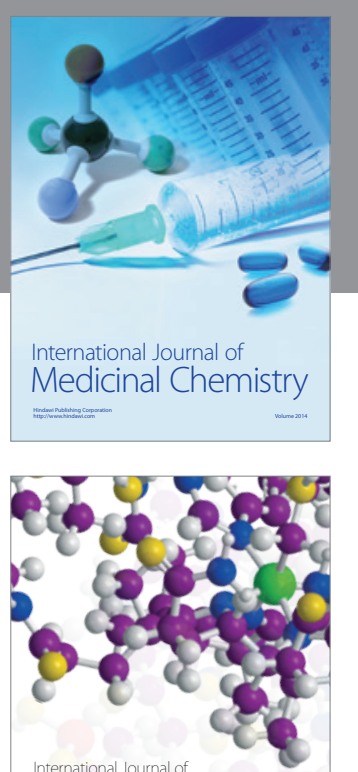

Carbohydrate Chemistry

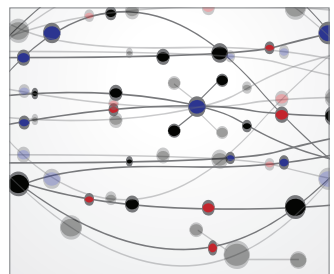

The Scientific World Journal
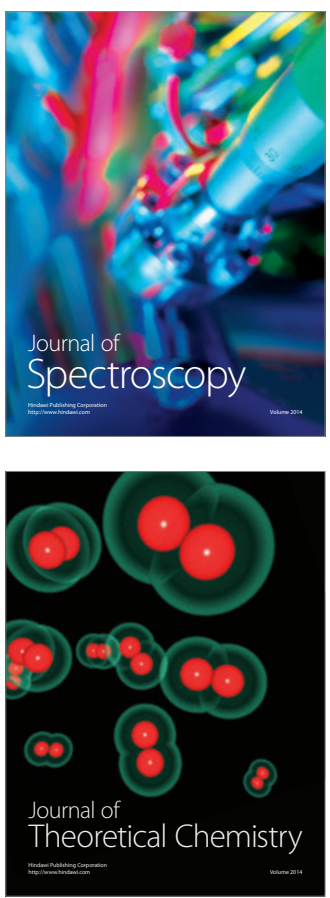
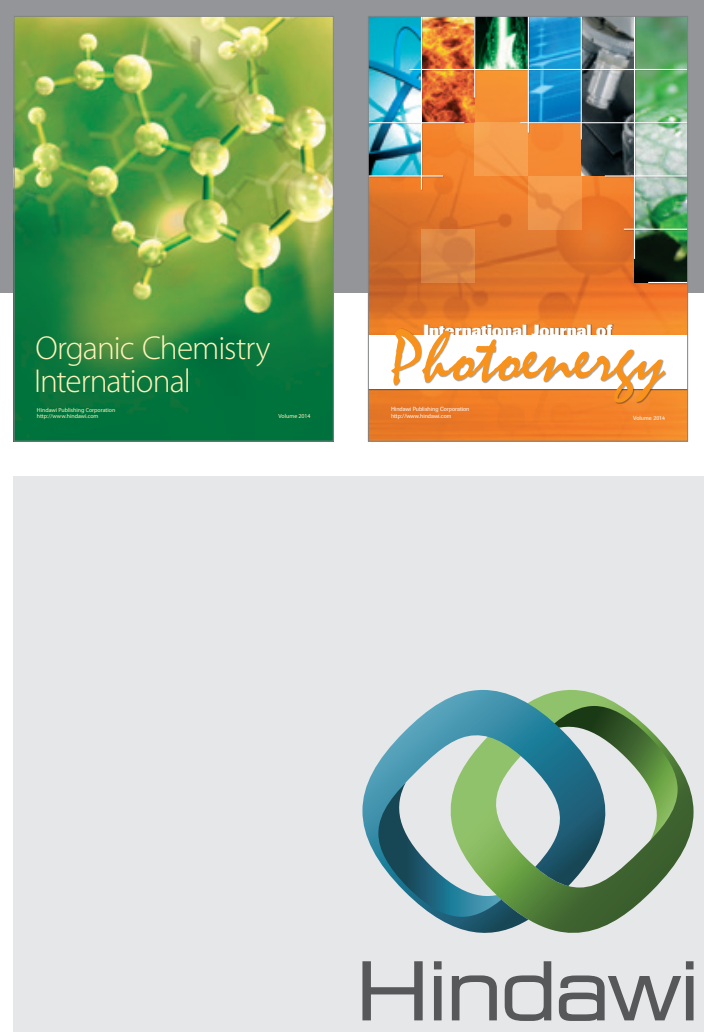

Submit your manuscripts at

http://www.hindawi.com

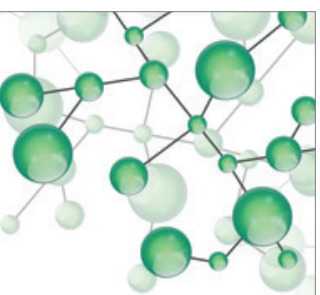

International Journal of

Inorganic Chemistry

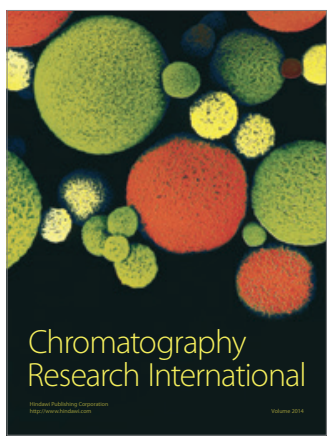

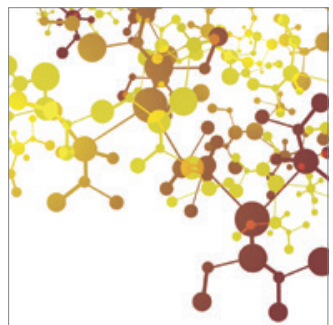

Applied Chemistry
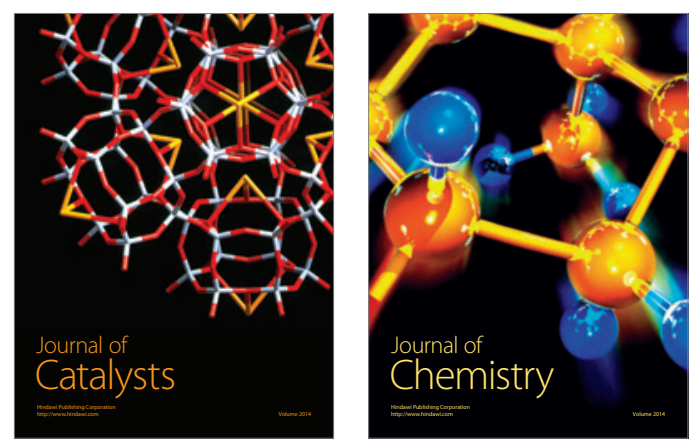
